\title{
Kosovar Resettlement Assistance Project in Greater Victoria
}

\section{Tomoko Okada}

\begin{abstract}
This paper describes a practical service model based on my field experience and outlines the process of Kosovar refugees' initial resettlement in Greater Victoria. Although an individual's age, social, educational, economic, and health conditions are some factors to influence refugee psycho-social adjustment, the continuum of resettlement is explained as dynamic, two-way, multifaceted, and long term. Resettlement does not end within one's lifetime, but it is rather an inter-generational evolution. This paper, however, only focuses on the first initial resettlement stage, which is critical to influence the whole continuum of inter-generational adjustment.
\end{abstract}

\section{Résumé}

Cetarticle décrit un modèle pratiqu :de prestationsbasésurmon expériences urle terrainetdonnelesgrandeslignesduf ocessus initial d'établissement de réfu jiés kosovars dans la grande région me tropolitaine de Victorıa. Malgrè le fait que l'âge d'un individu, sa condition sociale, son niveau d'éducation et sa situation économiquesontquelques-uns desfacteurs qui influencent l'intégration sociopsychologiquedu réfugié, lecontinuum du processus d'établissement est présenté commeétantdynamique,opérantdansles deuxsens, ayant des facettes multiples et s'étendantsurle longterme. Leprocessus d'établissementnes'arrêtepasaveclamort, maisestplutôtuneévolution degénération en génération. Toutefois, cet article n'examine quele stade initial d'établissement, périodecritiquepourinfluencertout le continuum d'ajustements entre générations.

Tomoko Okada is the Coordinator for the Immigrant/Refugee Settlement \& Integration Services Inter-Cultural Association of Great Victoria.
L'article met en valeur la source gouvernementale definancement et de soutien, ainsiqueles réactionspositivesde lacommunautéenversleprojet, lestensions entreparties.

This project posed many challenges to my role as an "immigrant settlement worker" with reference to my reflection on the process; notion of differences, "otherness", assimilation, integration, and refugee and immigrant stereotyping. Resources written from the settlement worker's perspectives are extremely limited due to settlement workers' English as their additional language background and their marginalized status.

This paper highlights the governmental sources of support and funding, as well as positive community responses towards the project, tensions amongeach stakeholder, bureaucratic paperwork, and possible backlash from other group members. This project is an example of how the traditional conventional social work practice cannot be a good tool to understand the whole problem situation of Kosovars. Structural social work, however, is an instrumental guideline for the broader perspective of assessing the needs of Kosovars towards better lives. In this paper, I use an Albanian word "Kosova" instead of the Serb word "Kosovo" which mostly used by the media.

\section{Introduction}

This paper analyzes and critiques the process of Kosovar Resettlement Assistance Project in Greater Victoria, which was undertaken by the Intercultural Association of Greater Victoria (ICA). I have been working for ICA for over ten years, where one of the major mandates is to assist immigrant and refugee settlement in Greater Victoria. Through my position at ICA, I had an opportunity to coordinate the Kosovar Project.
The primary purpose of this paper is to report how the project assisted Kosovar refugees in Greater Victoria. I will explore this project through the feminist, anti-racist, and structural social work practice to understand the human tragedy of ethnic cleansing. The major goal of this project is to assist the ethnic Albanian refugees, who were the targets of organized violence in the province of Kosova in Yugoslavia, through an easier transition of resettlement in Greater Victoria. Therefore, this paper will discuss the background of Canada's humanitarian evacuation policy, refugee push and pull factors, the situation of Canada as the host country, and the cross-cultural problem solving efforts to better the services in Greater Victoria.

For the scope of this paper, I will examine the cause of the mass exodus of Albanian Kosovar refugees: How the minority Serb government oppressed, marginalized, and alienated the majority Albanians. The second section of my paper describes the problem statement that has led me to develop the project. I will state the nature of the problem in order to provide better resettlement services in Greater Victoria, including a statement of my perspective (values, beliefs, assumptions, personal and professional interest, and experiences about this project). I will also present the possible causes contributing factors for the problem identified in the problem statement.

In the third section, I will focus on the specific objectives of this project and identify internal and external drivers, which supported the project, and the barriers that stood in the way of implementing better services. I will describe my action plan and the steps I took in my planned effort, including a time-line and the specific activities involved in each stage. I will discuss possible political and ethical considerations and their implications for my planned project. 
The last component of this paper will be my critical analysis of the project results, including the expected and unexpected outcomes. I will discuss my personal insights, the general learning process throughout this project. I will identify how my values, beliefs, and assumptions were challenged, and how these challenges affected my personal life and professional practice.

\section{Literature Review}

The preliminary literature was searched within a structural, feminist, and anti-racist social work reference. I examined publications such as Robert Mullaly's Structural Social Work: Ideology, Theory, and Practice (1993), Paulo Freire's Pedagogy of the Oppression (1994), Katrina Shields In the Tiger's Mouth: An Empowerment Guide for Social Action (1994), and Elaine Penderhughes' Understanding Race, Ethnicity, and Power (1989). Although these sources were backbone of the generalist, structuralist, and feminist practices, I realized how difficult it was to practice a realistic, attainable, and measurable outcomes within the present capitalist and liberal valued society. Mullaly (1993) asserts that the fundamental social work values of humanism are congruent with socialist paradigms, however, state power maintains the present status quo and restricts the eligibility of funding criteria. Shield (1994) claims the feminist principle of empowering unprivileged, vulnerable, and marginalized people, and validates my belief of the importance of immigrant settlement work. Nonetheless, I found that there were not enough resources available regarding the overall social welfare for immigrants and refugees. Armitage (1996) states in Social Welfare in Canada Revisited: Facing up the future that "Canada has undergone enormous economic, political, and cultural change [for twenty years]", yet the content does not include the welfare policy for immigrants and refugees.

The other initial resources provided up-to-date information and publications through Citizenship and Immigration Canada, and print material which described the situation in Kosova and the practical suggestions for working with refugees: Sponsoring Kosovars to Vancouver Island (Miller: 1999) and a Subcontract manual for Kosovar Resettlement Assistance Program. The publications from the United Nations High Commissioner for Refugees (UNHCR) also presented a useful guideline for settlement work: "A framework for People Oriented Planning: Taking Account of Women, Men, and Children Newcomers in Canada," and a quarterly magazine called "Refugees."

For the other resources, my major contact on understanding Kosovar culture and way of life was from five members of the Kosovar community, who helped me set up orientation for volunteers and joint-sponsors on Vancouver Island. Although psychosocial trauma and destruction is not a focus on this stage of resettlement, Martin-Baro (1994) claims three components of psychosocial trauma of survivors of organized violence: 1 . Social polarization and inequality exist. 2 . Institutional lies and circles of silence obscure social reality. 3. Survivors and their families, personal networks, and the societies of which they are members. Locally, three professionals (a female clinical counsellor and two male psychologists showed a strong interest in working on the issue of trauma.

\section{Background on Kosovar Refugees}

The Amnesty International reported on the decade of human rights crimes and prolonged organized violence in Kosova (1998) and that led to the NATO and the United Nations High Commissioner for Refugees' (UNHCR) involvement. The population of Kosova in 1998 was 1.5 million people, of which 1.3 million were ethnic Albanians (Malcolm, 1999). The dispute in the Balkans has been a major problem after years of conflict and increasing tension with Russia, and the nations were divided in Serbia, Montenegro and Romania without the consideration of ethnic composition in 1878. In 1918, Yugoslavia was created from the formerly occupied Ottoman and Austrian empires, and followed by Josip Tito's communist regime in Yugoslavia in 1944 (Kaplan, 1996). Kosova, has been an unrest region in the former Yugoslavia between majority Albanians (90\%) and Serbs (10\%) after the end of World War II.

In 1989, the Slobodan Milosevicgovernment stripped away Albanian Kosova autonomous status. For example, approximately, 350,000 ethnic Albanians sought asylum in Europe in the following decade. Albanians were not allowed to speak Albanian in public, the children were not allowed to attend schools, and there were massive dismissals from the government and professional jobs. The elected parliament was declared illegal and many were arrested and tortured under the brutal Milosevic regime (Miller, 1999). The oppression, discrimination, violence, and atrocities of ethnic cleansing resulted in an exodus of over a quarter of a million refugees from Kosova in 1999.

On March 24, 1999 NATOlaunched its 78-day air war. Within three days, ethnic Albanians began to arrive in neighboring countries in huge numbers: 444,600 refugees in Albania, 244,500 to Macedonia, and 69,900 in Montenegro. Due to the limited capacities in the receiving countries, more than 90,000 Albanians were transferred to 29 countries for temporary evacuation (Willkinson ed, 1999). Canada responded by taking 5,000 refugees under the humanitarian evacuation program.

\section{Kosovar Refugees in Victoria}

The Kosovar refugees have started to resettle in Greater Victoria under three different categories since April, 1999. The Fast Track program was the part of Family Reunification for refugees who have relatives in Victoria. Under this emergency evacuation, Citizenship and Immigration Canada extended family reunification for not only nuclear family members but also any relatives such as cousins, uncles, and nieces. Furthermore, family sponsors did not have to demonstrate their financial responsibilities for ten year sponsorships. Special Needs cases required serious physical or mental attention at oversea 
refugee camps, and the UNHCR prioritized to assist these people first.

Operational Parasol was for those individuals or families who had no relatives in Canada, and for those who stayed in Canadian sustaining camps for up to six weeks. Differently from the refugees, those who arrived directly from oversea camps in Macedonia and Albania under Fast Track and Special Needs, the people under Operational Parasol came through the Canadian Army BaseCamps: CFB Trenton, Greenwood, Aldershot, Kingston, and Halifax, where they spent four to six weeks receiving basic orientation for Canadian lifestyles.

Originally, in total, $120-150$ people were expected to resettle in Greater Victoria by the end of July, 1999, however, the actual total number of Kosovars was one hundred-one after the closure of the humanitarian evacuation program in September, 1999. Whileforty-six people under Fast Track and Special Needs programs were in the process of adjusting to their lives in their new environments, forty-five Kosovars arrived in Victoria under Operational Parasol assisted by the community joint-sponsors. The role of the community sponsors was equivalent to Fast Track relative sponsors who assisted in the social and emotional needs of the Kosovars.

ICA provided orientation for the Kosovars under Fast Track and Special Needs, while the refugees under the Operational Parasol program were supposed to receive full orientation programs in sustaining camps in the Eastern provinces before they settled in Victoria. Financially, the refugees received monthly cheques equivalent to the amount of provincial income assistance for food, clothing, accommodation, and transportation, in addition to the first initial starting cheque covering furniture and staples from the federal Citizenship and Immigration Canada (CIC).

\section{Problem Statement}

The "Kosovar Resettlement Assistance Project in Greater Victoria" brought together a wide range of individuals from a variety of community and institu- tional settings. As the Coordinator of Immigrant/Refugee Settlement and Integration Services, I received Kosovar refugees and assisted them in settlement orientation, and coordinated with other community services. This collaborative work posed many challenges due to the federal policy regarding government sponsored refugees, the funding requirements, and differing perspectives, beliefs, and positions taken by each stakeholder; CIC, NGO service providers, volunteers, and community joint-sponsors. The community politics was more problematic rather than a source to build alliances for coalition.

The local CIC selected the community sponsors whose services focus on social and emotional support to Kosovars under Operational Parasol. Sponsors who responded immediately to CIC's request were predominately from Christian church denominations. Volunteers also stepped forward to assist the Kosovars under Fast Track and Special Needs in their resettlement process.

What was missing at Kosovar arrivals were local resources and community collaboration, coordination, and communication between inter-governmental agencies such as CIC, Revenue Canada, the Ministry of Human Resources, NGO service providers, and community agencies. I, as a visible minority immigrant woman who had experienced settlement/adjustment difficulties in Canadian society, took this as a great opportunity not only to provide settlement services, but also to broaden my perspective by attempting to understand each Kosovar's individual experience. This enhanced my experiences and knowledge of the settlement and adjustment process in my profession.

\section{Causal Analysis}

I learned of the cause of Albanian Kosovars' mass exodus as deeply embedded in a long history of ethnic conflict in the Balkan region for over five hundred years (Kaplan, 1996). Pinderhughes claims:
The sense of commonality with others and the individual ethnic meaning that people develop as a result of their experiences have implications far beyond those of shared religion, national origin, geography, or race (1989:39).

A socio-economic and demographic analysis was a critical component of this project. There was an obvious lack of community resources. Furthermore, a local Albanian community was not well established. Only five families were identified and became the sponsors for Fast Track members, however, they were relatively new and many were still in the process of their settlement in Victoria.

I identified specific problems and barriers, that existed in this whole process. While considering differing points of view and governmental policies, these factors would have had a significant influence in providing better orientation services to Kosovars and training to sponsors and volunteers. The factors are:

-my lack of knowledge concerning Kosovar culture, language, and issues;

- lack of coordination among government bodies, local agencies, sponsors, and relatives;

-differing beliefs/viewpoints regarding settlement among sponsors and volunteers;

- lack of resources in the community such as Albanian-speaking professionals such as doctors and counselors;

-competition for funding among various agencies;

-stereotypes about Muslim people which community joint-sponsors and volunteers might have held. Their potential motivations to convert Kosovars to Christians.

My intentions to provide better services was influenced by the above factors, which also reflected to each stakeholder's personal conceptual baggage. I identified my level of knowledge concerning Kosovar people and their culture, the bureaucracy that seemed to be developing among government agencies, the diverse views on settlement that may be provided, and the limited avail- 
able resources as major elements of the problem. As ICA had been selected and contracted to provide Kosovar orientation, coordination among community agencies caused some tensions even at the early stage. I believed that through education and interaction with the Kosovars, the conceptual baggage each stakeholder carried was dealt with explicitly and implicitly and led to the elimination of stereotypes.

For analyzing some of the causes of the problem, I will focus on First Nations and the Feminist perspectives. As both perspectives emphasize the importance of working relationships with respect, I endeavored to respect not only Kosovars, but also volunteers, sponsors, and the other representatives. Also, my planned activities required Kosovars' active participation in the process of implementing the project. I started to compile interpreters' list from Albanians who have been here and newly arrived.

Through the lens of First Nations perspective, I learned the importance of distinctive cultural values, language, as well as self determination of the community. In fact, these theories affect me as a visible minority immigrant woman. Since I value my own heritage, I would not attempt to change or ignore the importance of Kosovar culture. In addition, gender analysis ensured that the project did not disadvantage women, elders, and children to address the needs and resources of the people holistically by respecting gender and the specific roles of women, men, the elderly and children.

\section{Goals and Objectives}

The major goal of this project was to assist Kosovar refugees in an easier transition of resettlement in Greater Victoria and becoming active and independent members of Canadian society. The time frame for this project began from the arrival of refugees to the initial phase of resettlement in the first three months depending the arrival date of each case (May-September, 1999). The specific objectives were:

to compile a list of local resources, such as doctors, dentists, optical services, and the other professionals; -to utilize interpreters who speak Albanian and to provide training for interpreters regarding ethical issues and self-care such as confidentiality, boundaries and power differences;

-to translate essential materials into Albanian;

-to provide support and training to joint-sponsors and volunteers regarding how to work with refugees;

- to organize basic community orientations covering the topics of education, law, health, community resources, finance, rental agreement, public transportation, and immigrant settlement process;

-to monitor carefully the symptoms of post-traumatic disorder and appropriately to refer and work with counselors;

- to advocate for the needs of Kosovar refugees in Greater Victoria

- to assist Kosovar refugees in establishing a local community development program.

\section{Drivers and Barriers}

Many intertwined layers of international, Canadian government, community, and individual levels of commitment, energy, values, and beliefs were identified as strong drivers for the Kosovar evacuation and resettlement effort. Also, as the external driver, the media played a key role to influence the decision making process. It is interesting to note that drivers can become a potential barrier as well, depending on the experiences and perception of the media, general public, government, and stakeholders with Kosovars.

The government's commitment to provide services and financial assistance was a driver. Certain policies have been generously changed such as waiving processing fees $(\$ 500)$ for the landing application, the airplane transportation fees, and increasing the benefit of Federal Interim Health Plan. In addition, the Federal financial assistance was extended to two years from general one year benefit, which would make the refugee transition easier than the other refugee groups.
Prior to the first arrivals of Kosovars, the project had been responded to with enthusiasm from various local community groups and individuals. Sponsor groups and volunteers were quick to respond to the call from CIC in overwhelming number; in fact, according to CIC, some sponsor groups had to be turned down. In general, the Canadian public has been receptive to Kosovar newcomers, as proved by their numerous charitable contributions. However, the underlying community politics were problematic in the initial meetings: Tension surfaced among the participants and conflicts arose. Eventually, ongoing open dialogue, consultation, and training for the community stakeholders eased some tensions and resolved conflicts.

The government served as a barrier. There was an enormous amount of paperwork required for each refugee since the initial contact with the earliest arrivals. Yet, I found that some of the essential information was often incomplete or incorrect. For example, some paper work was completed in overseas refugee camps, but this information was not relayed to the front-line level. Furthermore, correcting the official documents and information took several weeks, which caused delays in initial assistance funds. Due to the enormous amount of paperwork and the overwhelming stress levels of the refugees, very few people could recall much about the documentation. Therefore, unfortunately, a huge amount of paperwork was duplicated. Through some contacts with Albanians in Victoria, I learned that there was often a lack of trust between non-clan members. My initial consultations with Kosovar refugees through workshops and orientation helped me understand Kosovar cultural backgrounds. Personally reflecting on my experience as a visible minority immigrant woman, generated an even stronger commitment and interest to work this project.

\section{Strategy for Change}

Those facilitating the refugee empowerment process must understand not only refugees' new cultural context and 
codes but also the means by which they retain and value "old" cultural tradition and norms. Multiculturalism depends on this systemic interplay of forces (Howarth 1998).

The gender analysis and the peopleoriented planning was the base of my framework to achieve the goals. Therefore, it was an important strategy to ensure that this project did not disadvantage women, elders, and children, and to ensure that the project holistically address the needs and resources of Kosovar family by respecting gender and specific roles of women, men, the elderly and children. It reminded me that the refugees are active, productive, and resourceful people rather than passive victims awaiting support and assistance. In addition, a gender analysis and people oriented planning are tools, which facilitate project planning, implementation and evaluation.

Volunteer and sponsor training workshops were organized for a total of six sessions (each two hours), and covered topics such as understanding the Resettlement finance, Kosovar culture, ethical issues, and how to work with people experiencing with post traumatic stress. The regular meetings allowed me to develop trust and good working relationships with one another. Settlement is long-term, dynamic, multifaceted, and a two-way process. This kind of training for the host community was essential. As a result, I organized additional one-day workshops in Nanaimo and Courtney on Vancouver Island, while the monthly sponsors' support meetings continued in Greater Victoria.

An ethical consideration of this project was the social and financial power differences between Kosovar refugees and service providers including volunteers and joint-sponsors. Another ethical dilemma involved selecting appropriate interpreters as issues such as female/male, urban/rural, and clan/non-clan in order to provide more sensitive services. A potential issue I was concerned with was antiKosovar backlash in Victoria, because in spring, 1999 in the middle of arrival of Albanian Kosovars, Victoria Serb community was established.

\section{Conclusion}

Structural social work was an instrumental guideline as a broader perspective of assessing the needs of Kosovars and in changing to better resettlement situations. In general, the condition existed to provide the necessary assistance for the Kosovar refugees was much more flexible with timely positive community response. As a result, many refugee advocates question why such a strong dedication as opposed to other ethnic groups settling into Canada.

Traditionally each stakeholder in the project had worked separately and isolated from one another because of the perceived irrelevance of perspectives, beliefs, and values. Community coalition work could be challenging due to the reflection of the organizations' different history and experiences in the community. Obviously, there was no cohesive community to share the same vision with one another, however, this project brought an opportunity to break traditional barriers and division among the key stakeholders such as the CIC, NGO service providers, and church institutions. Therefore, the success of the project depended on each stakeholder's effort to work towards strong community collaboration. Through this project some consensus among the community members was expected by promoting greater exchange and networking. My personal strategy was to direct the discussion the way in which community organizations can work together to advocate on behalf of refugees and to influence the decision making process regarding immigration and citizenship issues.

Through this project, my interest was to pursue the feminist approach working with people from the margins, and I kept my journals, where it occurred to me new learning and the measure of psycho-social adjustments of the refugees. To monitor progress towards the goal, feedback from Kosovars and assisting volunteers and joint-sponsors was necessary. Once trust was devel- oped, I was able to seek feedback from the people.

This project made me question: What does the goal of settlement services mean to be? When does the settlement process end? What is the role of the settlement worker in this process? Although my experience with Kosovars was only short period of settlement continuum, Counseling across cultures (Pederson: 1996) describes the settlement and integration theory from a holistic view. As Cheboud claims that "the goal of the [structural] theory is to create change, that is progressive, holistic, social, and environmental, it provides key ingredients to understand the needs and the effects of change" (1998:33). Kosovar's personal experience can influence political decision. I feel responsible as an Immigrant settlement worker not only to empower refugee individuals but also to influence the structural level in the issue of overall refugees' resettlement.

\section{References}

Amnesty International. (1998). "Kosovo: The evdence”. London: AI Publishing.

Armitage, Andrew. (1996). Social Welfare in Canada Revisited. Toronto: Oxford University Press.

Bishop, Anne. (1994). Becoming an Ally: Breaking the cycle of oppression. Halifax: Fernwood Publishing.

Cheboud, Elias. (1998). The African Immigrants Use of Traditional Healing Practices as Part of Their Process of Resettlement into Canadian Society. Vancouver, B.C.: University of British Columbia.

Freire, Paulo. (1970). Pedagogy of the Oppressed. New York: Seabury.Friedrich, $M$. J. (1999). "Addressing Mental Health Needs of Balkan Refugees: Journal of American Medical Association, August 1999, pp. 422-423.

Howarth, Ann. (1998). “A framework for people for people oriented planning: taking account on women, men, and children newcomers in Canada". Ottawa, Ontario: United Nations High Commissioner for Refugees.

Kaplan, Robert. (1996). Balkan Ghosts: Ajourney through history. New York: Vintage Books.

Malcolm, Noel. (1999). Kosovo: A Short History. New York: Harper Collins. 
Martin-Balo, Ignacio. (1994). "Psycho-social tauma and trauma culture resulting from prolonged periods of war and organized violence" in Liberation Psychology. A. Aron \& S. Caron (edts). Cambridge, Ma: Harvard University Press.

Miller, Betty. (1999). "Guide for sponsoring Kosovars to Vancouver Island". Victoria, B.C.

Mullaly, Robert. (1993). "Structural Social Work: Ideological Basis and Conceptual Overview" in Structural Social Work: ideology, theory, and practice.
Toronto, Ontario: McClelland \& Stewart Inc., pp.117-128.

Ng, Roxanna. (1996). The Politics of Community Services. Halifax: Fernwood Publishing.

Pederson, B.P.(1996). Counseling across Cultures ( $4^{\text {th }}$ ed.) Thousand Oaks, California: Sage Publications.Pinderhughes, Elaine. (1993). "Understanding Ethnicity" in Understanding Race, Ethnicity, and Power. New York: The Free Press. pp39-69.

Shield, Katrina. (1994). In the Tiger's Mouth: an empowerment guide for social action.
Gabriola Island, B.C:New Society Publishers.

Stephenson, Peter. (1991). The Victoria Multicultural Health Care Research Project. Victoria, B.C.: Trans Cultural Consulting Service.

Wharf, Brian. (1990). Social Work and Social Change in Canada. Toronto: McClelland \& Stewart Inc.

Ray Wilkinson (ed). (1999). "Cover Story: Kosovo's race against winter" in N116, 1999 Refugees. Geneva, Switzerland: UNHCR. a

\section{Background Information on the Centre for Refugee Studies}

The Centre for Refugee Studies (CRS) is an organized research unit of York University. Founded in 1988, the Centre for Refugee Studies is successor to the Refugee Documentation Project created in 1981 for the conservation and analysis of research documents and data collected by Operation Lifeline during the crisis of Indochinese Boat People. In 1991, CRS was designated as a Centre of Excellence by the Canadian International Development Agency (CmA).

The Centre for RefugeeStudies fosters interdisciplinary and collaborative research inall ofits undertakings. The efforts of CRS are focused in areas related to a comprehensive research programme expanding from theoretical to institutional research. In carrying out this research, CRS networks with Canadian and international developmentagencies andacademicinstitutes. CRS invites scholars from abroad to participate in the research. Canadian and international students are supported by CRS to undertakefield studies and conduct related research. Joint research activities with institutions in the developing counties are underway. CRS plays a significantrolein an advisory capacity with Canadian government and other agencies.

In our education initiatives, the general Certificate programme allowsstudents in the undergraduate programmes (Faculty of Arts of Environmental Studies, Atkinson College and Glendon College) to register specifically forthe Certificate and to specialize formally in the area ofRefugee and Migration Studies and to be awarded the Certificate concurrently with the BA or BES. Students who already have an undergraduate degree can be admitted as special students by the relevant faculties and complete the requirements to receive a Certificate in Refugee and Migration STudies. The Craduate Diploma programs offers incentives and recognition to students whose academic focus is refugee related. issues. The Graduate Diploma programme was developed and passed by the Graduate Faculty Council and subsequently by the YorkS Senate in April 1991, The Diploma is awareded concurrently to the graduate student who complete the diploma and the degree requirements.

Our communications inittatives involve acquisition efforts through data collection in our Andrew Forbes Resource Centre, a comprehensive publications programme including the periodical REFUGE, and a full programme of seminars, workshops, and conferences.

(C) Tomoko Okada, 2001. This open-access work is licensed under a Creative Commons Attribution-NonCommercial 4.0 International

License, which permits use, reproduction and distribution in any medium for non-commercial purposes, provided the original author(s) are credited and the original publication in Refuge: Canada's Journal on Refugees is cited. 